\title{
A basic design for a multicriteria approach to efficient bioenergy production at regional level
}

\author{
Zoë Hagen
}

\begin{abstract}
Background: In Germany, government policies supporting the growth of renewable energies lead to a rapid increase in energy crop cultivation. This increase is linked to possible conflicts between different sustainability goals which so far have been rarely considered in the planning procedure.

Methods: This article looks at different approaches of assessment and planning methods on a region-specific level. It describes the methodology of the project Efficient Bio-Energy in the Perspective of Nature Conservation - Assessment and Recommendations to Protect Biodiversity and Climate which aims to establish the basis for an integrated sustainability assessment of energy crop cultivation for decentralized energy production in Germany and has been conducted by the author. The method takes into account the three main requirements of agricultural profitability, greenhouse gases (GHG) efficiency, and environmental sustainability of energy crop cultivation for decentralized energy production and has been applied for two sample regions.
\end{abstract}

Results: Using ArcGIS, the suitability of energy crops can be displayed, and regional aspects can be considered by overlaying and intersecting the individual output of all three requirements. This allows the definition of 'no-go' areas as well as the overall estimation of the maximum sustainable production capacity for each energy crop or energy path in a specific region. It enables an estimation of the profitability and GHG efficiency of energy crop cultivation paths at regional or communal level under consideration of different indicators for environmental sustainability.

Conclusions: The article closes with a discussion of the methodological challenges of this integrative method. The conclusion gives an outlook in which planning and policy processes could be beneficial to apply such an integrative method in order to assess the suitability of certain landscape areas for energy production paths.

Keywords: Sustainable biomass use, Assessment methodology, ArcGIS, Biogas use, Agricultural profitability, Climate efficiency

\section{Background}

Recent German climate and energy policies such as the Renewable Energy Sources Act (EEG), ${ }^{a}$ the biofuel quota law, and similar policies have resulted in an increase of energy crop cultivation in Germany in the last few years. The expanding production of energy from renewable sources as biomass has resulted in an additional need for land allocation for bioenergy production [1]. The federal government's expansion and production goals regarding bioenergy are accompanied by questions about land capacity limitations, as current policy processes are the

Correspondence: hagen@ztg.tu-berlin.de

Environmental Assessment and Policy Research Group, Technische

Universität Berlin, Sekr. EB 5, Straße des 17. Juni 145, Berlin D-10623, Germany main cause for intensive changes in land management. Land has a significance for nature and climate as a habitat for flora and fauna ensuring biodiversity by reducing climate gas emissions, on the one hand, and for human demands as a cultural heritage, a tourist attraction, and a ground for the production of animal fodder and foodstuffs, as well as energy, on the other. Since the balance between different land functions is sensitive to radical changes, it has to be ensured in a continuous process. Whereas the increase of bioenergy production is originally driven by the government's climate change reduction goals, a sustainable and integrative land use management becomes more and more the subject of intense discussions [2].

Bioenergy production can make an important contribution to the reduction of greenhouse gases (GHG) and, 
thus, to the realization of Germany's climate protection goals. Not only the impact of the bioenergy facilities themselves is relevant to the environment but also the cultivation of the crops that feed them. Current subsidy policies lead to higher shares of certain energy crops such as maize and rapeseed [3]. This is a result of the EEG, which rewards a facility's energy output and, thus, implicitly supports the cultivation of certain substrates. The majority of Brandenburg's farmers have viewed this positively and have proposed a continuous expansion of biomass production for energy production, assuming an increase from currently $4 \%$ to up to $22 \%$ [4]. Such an expansion which is explicitly proclaimed by the National Biomass Action Plan would certainly result in increased pressure on the land as well as an increase in total cultivation and higher productivity [5]. Criteria for environmental sustainability play a secondary role both in political discussions and calculations of biomass potential [6]. So far, energy crop cultivation largely avoids policy regulations wished for under an integrative sustainability point of view. The entire agricultural cultivation has not been the subject to environmental assessment or any quota regulation regarding the cumulating effects of cultivation of any kind of crops on environmental goods, for example. ${ }^{\mathrm{b}}$ To date, this is dependent on the farmers how they respect good agricultural practice (cf. [7]).

However, the cultivation of energy crops does not automatically have a positive effect on the varying goals pursued by energy policy. It can, e.g., lead to a negative balance of greenhouse gases if it results in certain direct or indirect changes in land use $[8,9]$.

Other protected natural goods such as biological diversity, soil, and water can be negatively affected by inadequate cultivation [9-11]. Further effects include changes in species composition or even extinction, a problematic result of increased pressure on land use in terms of biodiversity because it can, for instance, change a habitat's structure [11,12].

In many cases, there are conflicts between sustainability goals in the areas of biodiversity, soil, and water protection, on the one hand, and farmers' sovereignty and profit, on the other. Sometimes, there is also a lack of acceptance of affected inhabitants or tourists, mainly in the course of facility approval [6]. Competing goals are as follows:

- GHG efficiency (reduction of greenhouse gases),

- environmental sustainability of crop cultivation and the avoidance of indirect damages such as the loss of biological diversity, the influx of invasive species, the erosion of the landscape,

- maximization of space efficiency and the economic yield, and

- local acceptance for land use changes.
Since there is a necessity of creating a balance between these competing goals, this article will discuss the regional requirements for an integrative assessment of energy crop cultivation. Different approaches which were developed to assess singular aspects of bioenergy use will be integrated, and the methodological challenges of such an integration will be discussed. In conclusion, the possible benefits regarding the central demands and opportunities for governance within the current planning system in Germany will be presented.

\section{Field of research}

For the assessment of energy crop cultivation regarding the above mentioned goals, studies on the output potential as well as geographic information system (GIS)-based approaches exist. This article will only focus on the latter since it is primarily concerned with the assessment of biomass cultivation for energy use on the regional level and not with an estimation of the maximum yield. ${ }^{\mathrm{C}}$ Four GIS-supported 'implementation or test' methods for regional criteria with differing foci exist so far.

The approach of Jandewerth ${ }^{\mathrm{d}}$ [13] focuses on logistics and technical aspects. The GIS' capabilities are able to identify potential biomass production sites and constraints on the production, preparation, and an optimized distribution of biogas via the existing gas distribution grid. The approach aims at overcoming problems within the logistical production chain. Possible sites for biomass crop cultivation are determined by a process of excluding legally-protected areas and overlapping suitable sites with logistical feed-in facilities, thus, helping to identify optimal locations for bioenergy production ([13], and compare for [14]). From the abovementioned goals, especially environmental goods like the loss of biodiversity are not sufficiently considered.

In the UK, an interdisciplinary team ${ }^{\mathrm{e}}$ developed an approach which assesses the impact of multiyear crops on the landscape, the economy, and environmental goods (mainly multiyear cultures and short rotation coppice - KUP). The research project included basic research on the impacts of cultivating Miscanthus, willow, and multiyear crops on the soil, the biological diversity, and the water regimes and integrated them in a physical model (JULES) ( $c f$. $[14,15])$. Tourism and socioeconomic effects are also assessed according to public participation requirements. A questionnaire survey has been conducted to find out peoples' attitudes toward energy crop planting and biomass power stations. The latter indicated that the energy infrastructure and the scale of bioenergy power plants are the crucial points for acceptance. ${ }^{\text {f }}$ GIS is also used here as a tool to map changes in land use and the resulting constraints. Unfortunately, some data are not simply transferable to Germany because of differing habitat structures and 
sensitivity of nature which are region-specific. In addition, the project has mainly regarded multiyear crops and, therefore, only a small percentage of Germany's energy crops. Transferable is the approach of analyzing inhabitants' and tourists' sensitivity towards the loss in axes of view and sense of home through the cultivation of multiyear crops; the respective approach has been adopted to the methodology which is presented here.

Brozio et al. have developed a model that uses a topdown approach to illustrate the economic output of different types of energy crops at community level within the Baltic Sea Project [16]. ${ }^{g}$ For the estimation of biomass output, a biomass yield model is used $[17,18]$. It determines the yearly biomass revenues for regionally established and site-specific crop rotations. The suitability and quality of energy crops are determined by precipitation rates and soil quality, which appear to be too limited as criteria for environmental sustainability. The model focuses on estimates of biomass potentials at regional - or county - level or even in the immediate surroundings of bioenergy facilities (S Brozio, personal communication). The estimation is based on the approach 'Landsize $\times$ potential average output' and focuses on classic substrates, such as silage maize and liquid manure, thus, failing to give a regionally specific assessment of environmental sustainability.

Schultze et al. [19] focus on a particular assessment of the environmental impact of bioenergy crop cultivation at a regional level. The assessment includes all biotic and abiotic goods and nature functions, apart from cumulating effects and peoples' sense of home. Using ecological risk analyses, established energy crops are assessed on a culture-specific basis. The results are measured by a three-level scale and spatially defined. Overlapping the actual/planned amount of bioenergy facilities helps to identify areas that are environmentally at risk. The project does not consider other sustainability goals as for instance climate protection.

For a sustainable expansion of bioenergy use at regional level, the above-mentioned sustainability goals regarding the reduction of greenhouse gases for climate protection, agricultural efficiency, and environmental sustainability should equally be taken into account when assessing the cultivation of energy crops. To date, an integrated approach does not exist. The existing methodologies are concerned with single aspects of these goals, which should be considered at regional level during the course of planning. Site-specific assessments on cumulative effects and risk avoidance during further expansion of biomass production are, thus, indispensable ( $c f .[15,20-22])$.

\section{Methods}

In the following, an assessment methodology will be described that seeks to integrate three main assessment criteria: (a) agricultural efficiency, (b) climate efficiency, and (c) environmental sustainability. This approach was developed within the research project Efficient BioEnergy in the Perspective of Nature Conservation Assessment and Recommendations to Protect Biodiversity and Climate [9] and is based on Schultze et al. [19].

The leading research questions of this project were issues such as the methodological compatibility of the three criteria as well as the resulting synergies from an integrated view. The methodology also uses GIS since the often-requested site orientation in assessment and governance $[8,20]$ can be graphically grasped by this tool.

The method was applied in two sample regions (SaaleHolzlandkreis (SHK), Thueringen and OstprignitzRuppin (OPR), Brandenburg). It aims at developing a basis to assess the current cultivation scenery as well as to identify optimized cultivation systems respective to local scenarios, since referring to local conditions can be regarded as the most appropriate way to handle existing uncertainties confronting climate change mitigation [23].

\section{Agricultural profitability}

Agricultural profitability is one of the most important criteria for farmers' decisions: It is defined as the maximum yield per surface unit. ${ }^{\mathrm{h}}$ The selection of bioenergy crops assessed in this project comprises the widest possible spectrum from annual oil plants (rapeseed) to sugar and starch plants (sugar beets, wheat, and rye), biogas plants (clover grass, maize, rye/barley whole-plant silage, cup plants (Silphium perfoliatum), and fodder rye/fodder millet) to permanent crops (poplar and Miscanthus) that are used in decentralized agricultural plants on a small scale (such as at $190-\mathrm{kW}_{\mathrm{el}}$ biogas plants).

The energy efficiency of bioenergy plants and the return from the EEG represent the most important parameters of agricultural profitability. Profitability is also strongly influenced by regional parameters such as the soil quality, ${ }^{\mathrm{i}}$ the achieved output (market revenue) of a particular yield, the direct costs (seeds, fertilizer, pesticides, and soil preparation), the operational costs (machines, maintenance, tax write-offs, and labor costs), as well as the cost of the land (rent) [9] (cf. Figure 1). The crop-specific results are transferred into a rating system with a three-stage evaluation scale ( $c f . \mathrm{a}, \mathrm{b}$, and $\mathrm{c}$ in Figure 2) in order to match with the GHG emissions and the environmental sustainability later on. For the highly volatile agrarian market prices, the average of the last year prices was taken, and a price range was defined. The results take EEG compensation for biogas crops into consideration. A balanced nutrient content in the soil has been taken as a given, and fertilizer costs have therefore been calculated on withdrawal. 


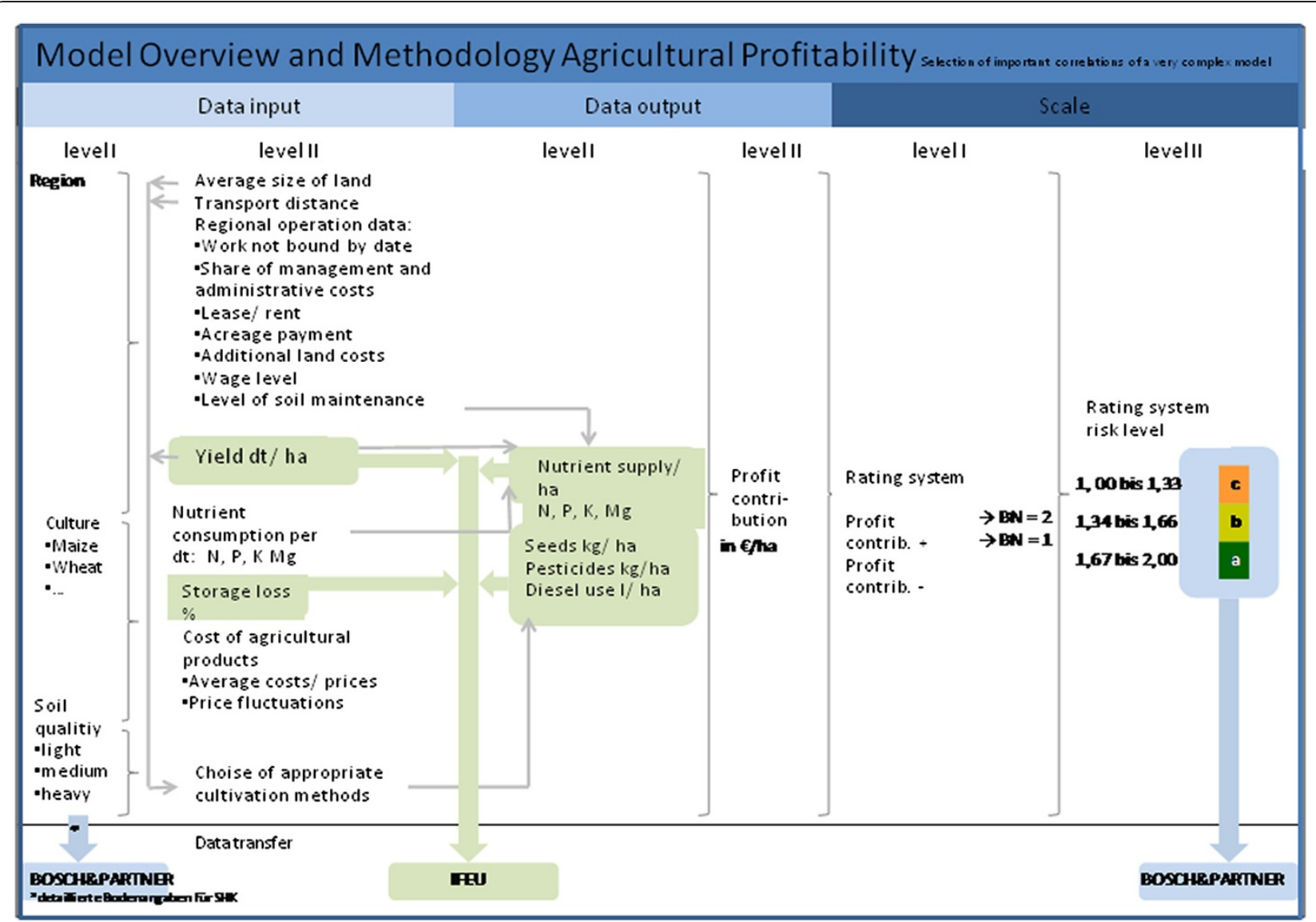

Figure 1 Model overview and methodology for agricultural profitability. Modified from Beck in [9].

\section{GHG efficiency}

The assessment of the GHG efficiency has been carried out using a life cycle assessment ${ }^{j}$ that compares the entire lifespan of the selected bioenergy crops from cultivation and processing to energy use with the life cycle of fossil fuels ( $c f$. Figure 3). The analysis combines energy crop species with different conversion technologies, energy uses, and bioenergy paths. The observed crop cultures are analyzed using three agricultural reference systems (cultivation of energy crops on fallow land, cereal cultivation sites, and permanent grasslands) for both direct changes in land use (dLUC) and for indirect changes in land use (iLUC) using the substitution method [9] (cf. Figure 3).

\section{Environmental sustainability}

The environmental protection assessment is carried out by analyzing the ecological risk for landscape functions according to Von Haaren [24] for all selected energy crop species. Their risk classification at a particular site arises from the impact intensity of the cultivated crop and the sensitivity of the habitat. The risk of erosion due to the cultivation of maize, for example, is influenced by local constraints such as soil type, soil gradient, or even climate conditions.

Considering the possible conflicts between the impact of energy crop cultivation and the aims of environmental protection, the following environmental indicators and related criteria were shown to be relevant for determining the biomass potential (cf. Figure 4):

- Soil: erosion sensitivity (water/wind), sensitivity to densification, sensitivity to harmful substances;

- Water: ground water supply, sensitivity according to the aims of the Water Framework Directive, retention function (water);

- Biological diversity/biotope function: environmental protected areas, biotope functions and species protection; and

- Landscape: landscape scenery and recreation, loss of important axes of view, and changes in visual aspects and characteristics of the landscape.

Compared to the previous project, a number of modifications and alterations have been made. The evaluation considers only farmland. An agrarian use is 


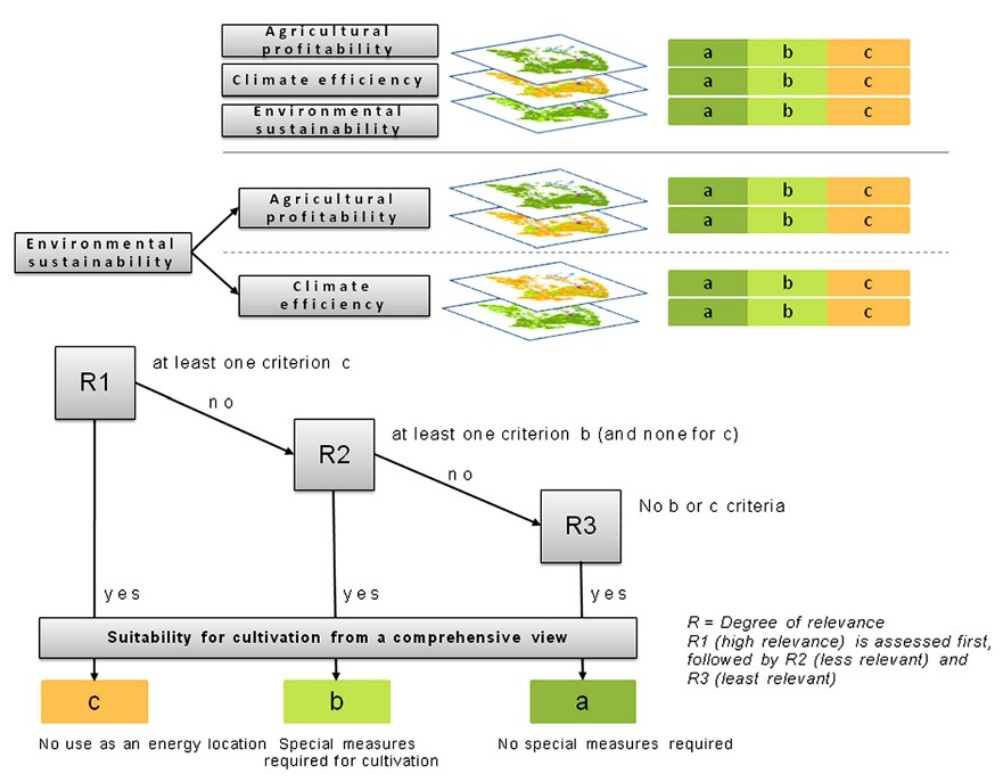

Figure 2 Blending of the criteria. Of agricultural profitability, climate efficiency and environmental sustainability, and transfer to land categories (own results) [9].

given; therefore, all evaluations were performed compared to the impact by the cultivation of winter rye, the actual most cultivated crop in the region. The impact of the cultivation of particular cultures, to be juxtaposed to the sensitivity of nature's goods, has been determined with the help of expert surveys [25] and has been newly complemented and confirmed by the current research results ( $c f$. Figure 5). In order to ascertain the sensitivity of landscape functions, a number of linking rules can be used (for example from Marks et al. [26] or NIBIS, as described in the literature [27]). Linking rules allow for estimates with the help of a few, mostly readily available parameters like soil type and gradient for soil erosion from water. Compared to the previous project, they have been simplified, if possible, or updated, or completely changed as, e.g., the assessment of landscape aspects, for which we differentiated between the view axes of and the recreation function instead. Changes of visual aspects and the sensuous experience of the expected region-specific cultural aspects determine the degree of sensitivity for both tourists (recreation as a protected good) and inhabitants (recreation and sense of home as a protected good). Sensitivity is high for axes of view, touristic trails, and nature parks. The impact of crops differs in height and density, regional parameters such as quantity and dispersal, and whether the crop is characteristic for the region.

The assessment of water quality has been included in order to meet the requirements resulting from the implementation of the Water Framework Directive. The approach is suitable to display the impact of crops deriving from the input of pollutants as nutrients and herbicides or pesticides, or the input of soil particles through wind and/or water erosion. ${ }^{\mathrm{k}}$

For the two model regions, the impact intensity of the cultivated crops was blended with the sensitivity of sites and displayed via a decision tree ( $c f$. Figure 6), resulting into three different site categories $(c f . \mathrm{a}, \mathrm{b}$, and $\mathrm{c}$ in Figure 2), leading to different recommendations of agricultural use (see Figure 2). The results are provided in the form of sensitivity maps. Interlaying the sensitivity maps with the impact of the specific crops, precise risk and suitability maps for specific energy crops can be generated. The generated risk maps help to identify the area-specific root causes of risks (e.g., in Figure 7).

\section{Integration of the assessment results}

Subsequent to the individual assessment of the three main criteria, the results were blended ${ }^{1}$ with each other for exemplary energy crops without weighting them (cf. Figure 2). This allows an estimation of the trade-offs the regions would have to accept for energy path scenarios. A transparent visualization of these trade-offs is not provided by the current planning system $(c f .[20,22])$.

The integration of the results is possible for assessing the environmental sustainability and both the agricultural profitability and GHG efficiency. Due to the differing system boundaries, it is not possible to blend GHG efficiency and agricultural profitability. The assessment of the latter would have to be expanded to the transport and societal costs. However, the individual results 


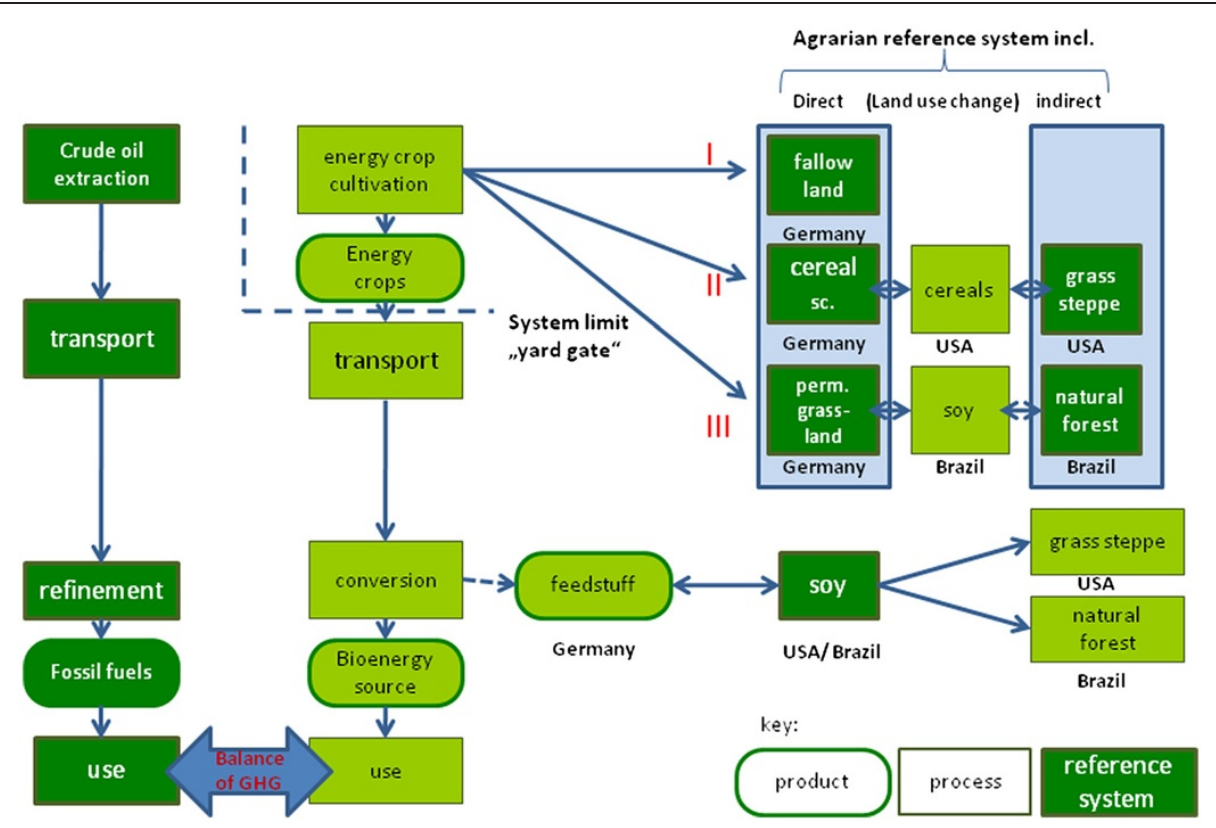

Figure 3 Illustration of the life cycle assessment. For the determination of the GHG emissions regarding the requirement of the GHG efficiency. The system limit 'yard gate' indicates the system boundaries of agricultural profitability [9].

regarding GHG efficiency and agricultural profitability are very similar - apart from the extremely diverging values for the cultivation of crops on greenland (organic soils) so that no conflicts are expected with the actual use in the assessed regions regarding the quantity of biomass production. The dispersal has not been assessed as the data have not yet been available.

\section{Results}

The project generated results concerning each criterion (regarding both methodological aspects and the assessment of the different energy crops), results regarding the possibility of combining the criteria-specific values, and, last but not the least, hints for the use of the methodology within the German planning system and for further research.

Regarding the agricultural profitability, the obtained results show that a variety of crop species can be cultivated with an acceptable economic yield ${ }^{\mathrm{m}}$ (cf. Figure 8$)$. Theoretically, this leaves leeway for the consideration of aspects of bio- and agrodiversity since the results show a factually higher variability than the actual concentration on one of the crop such as maize for bioenergy paths. In Thueringen, for example, the largest profit margin on medium soil results from the cultivation of cup plants (S. perfoliatum).

However, the financial yields differ so strongly that it is obvious that there are clear preferences for single cultures (cf. Figure 8). Crops for bioenergy use are privileged by compensation from the EEG and, thus, by the efficiency of electricity production, as the EEG recompensates the effective energy output. It is difficult, though, to evaluate and compare agrarian costs as the sector is highly influenced by different funding systems, and there is no real production cost or market to compare with. This is caused by the fact that, for example, maize used for animal fodder has no market price but is instead calculated by the price a plant operator would be willing to pay for, which is not necessarily related to the energy output or any alternative use of that crop.

Costs for transport outside of the farm ground are not taken into account here. Since transport costs vary according to the energy density of a substrate, the evaluation results could change considerably in this way. The possibility of recirculating fermentation rests, and the resulting lower fertilization costs are also not considered.

In the future, the initial state of nutrient supply to the soil and the preexisting impairments should be considered, whereas in this case, optimal conditions are assumed. The results cannot be generalized as the crop yields strongly depend on regional parameters such as soil conditions or climatic characteristics, for example, water supply.

Regarding the assessment of GHG emissions of the selected bioenergy crops, the largest reduction of greenhouse gases can be observed from the stationary use of poplar and Miscanthus. In the reference system 'fallow ground,' there is a positive greenhouse gas balance for all bioenergy paths; in other words, it can lead to a 


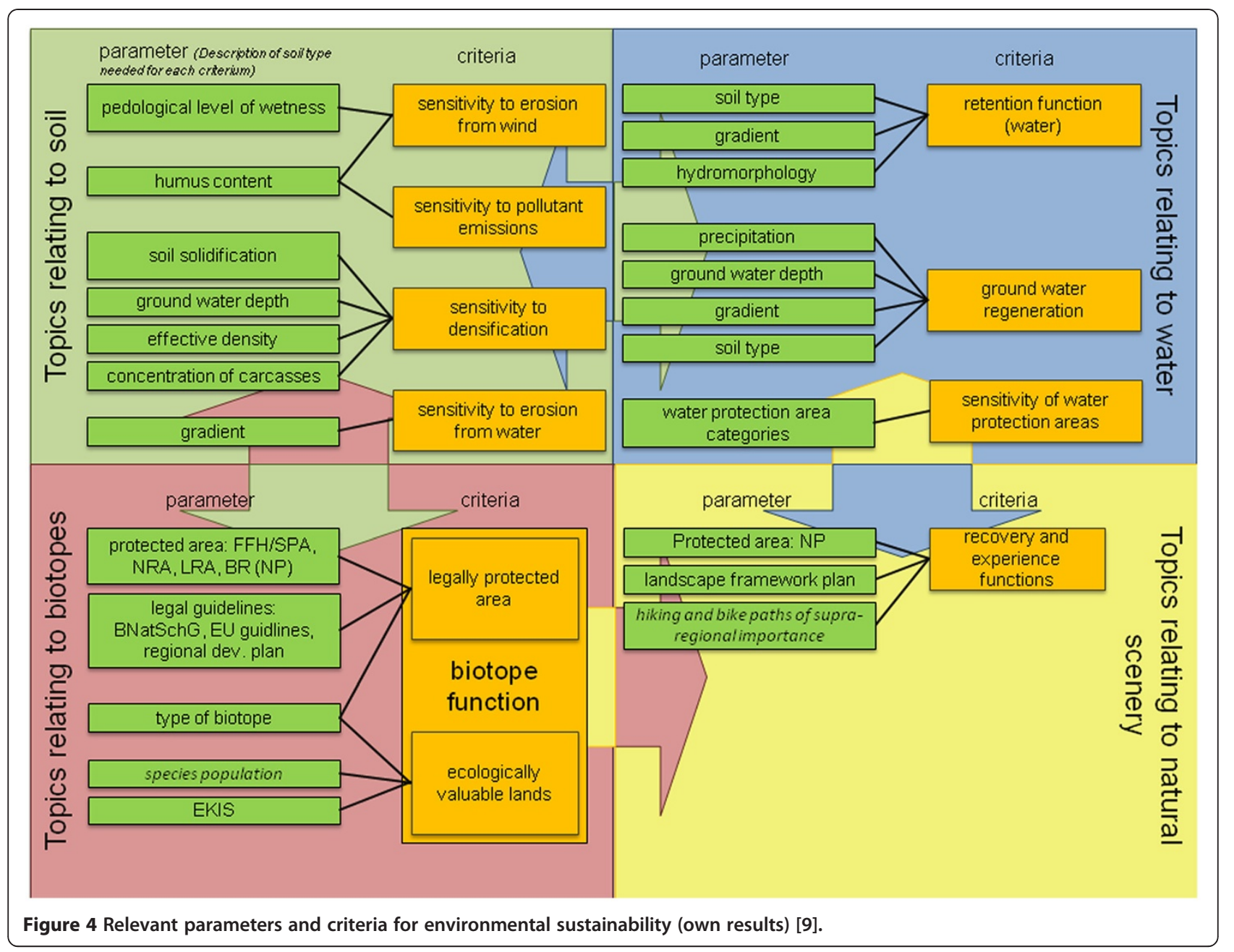

reduction in greenhouse gases compared to nonrenewable energy sources. Biogas and biomethane from clover grass as well as bioethanol from poplar (poplar only in Ostprignitz-Ruppin) in the 'cereal' reference system show that indirect land use changes result in a negative greenhouse gas balance. The 'grassland' reference system demonstrates that all bioenergy sources (with the exception of electricity and heat from Miscanthus in the Saale-Holzlandkreis) result in a negative greenhouse gas balance due to indirect changes in land use. In contrast, the simple fact of plowing grasslands on fen sites presents a clear negative balance even for direct changes in land use, which is in synergy with the goals of environmental sustainability. Figure 9 outlines the results of the greenhouse gas balance, with ' + ' and '-' symbols indicating a positive and a negative balance, respectively. Symbols in brackets mean that the results do not pertain to all bioenergy paths for the crop species in question. The degree of $\mathrm{CO}_{2}$ savings vary significantly, as exemplified in Figure 10 for various crops within the cereal cultivation site/indirect land use scenario.
The additional demand of arable land to grow energy crops increases the pressure on land use. Changes in land use result in a number of mostly negative environmental impacts, including increases in greenhouse gas emissions as a consequence of changes to the carbon stocks at the affected sites ( $c f$. Figures 9 and 10). This change or alternative use of land is called an agricultural reference system [28]. The agricultural reference system also covers all changes in land use that are induced by the allocation of land for energy crops.

The analysis demonstrates that agricultural reference systems, including direct and indirect land use changes, have a significantly larger influence on the values of GHG emissions than the selection of crop species, the conversion technology, or the target product does. With some distance, other parameters that determine the results are the cultivation methods as well as the conversion of biomass. The GHG efficiency is also clearly dependent on regional factors, for instance, on the question of whether fallow land is plowed for energy crops 


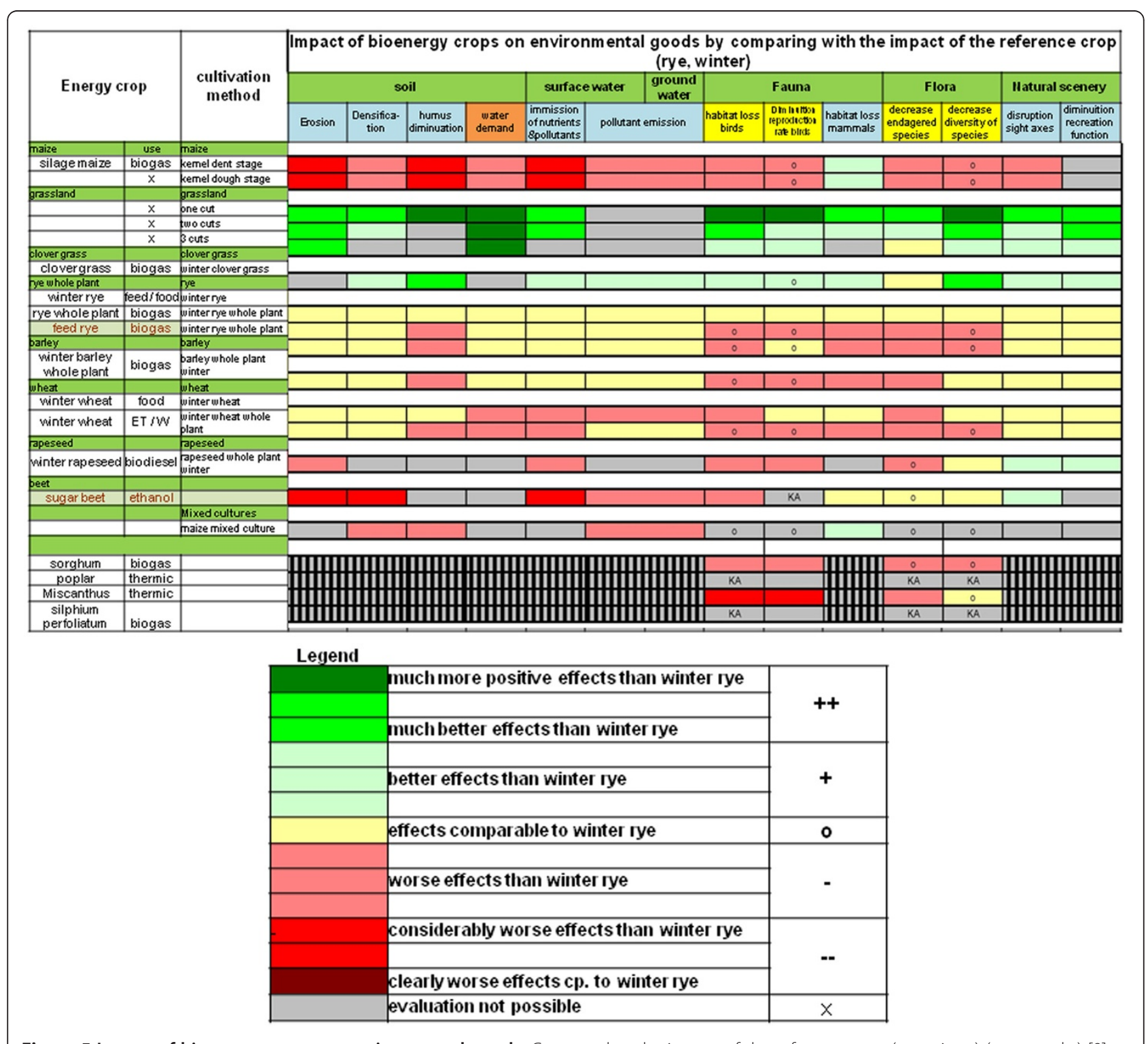

Figure 5 Impact of bioenergy crops on environmental goods. Compared to the impact of the reference crop (rye, winter) (own results) [9].

or whether it displaces current food or animal fodder production.

Environmental sustainability resulted to be the most site-dependent and, therefore, the most strongly limiting criterion regarding the dispersal of energy crops. The results were obtained for the model regions indicating that there are adequate sites for every assessed crop to be grown in an environmentally sustainable way. The results also include clear risk areas and possible alternative sites. Whether the size of these areas is sufficient to meet the regional goals for the production of bioenergy has not been estimated in this case. Problematic is not only the quantity but also the regional dispersal of energy crops because of cumulating effects, which cannot be adequately displayed for none of the criteria using the current methodology. These results clearly demonstrate the need for a regulation of the regional allotment of biomass cultivation. ${ }^{\text {n }}$

Cumulative aspects cannot be displayed at present, but they have a considerable impact, especially regarding land use as a whole. Therefore, an integrative view on land use for fodder, food, and energy production appears to be more sensitive than assessing only singular aspects such as the impact of biomass production.

The data for the evaluation of the sensitivity of the landscape scenery and the biological diversity are only partially available. In this approach, for the criterion biodiversity, it would have been necessary to examine the possible impacts properly which should include $a$ modelization of crop rotation. In order to make the 


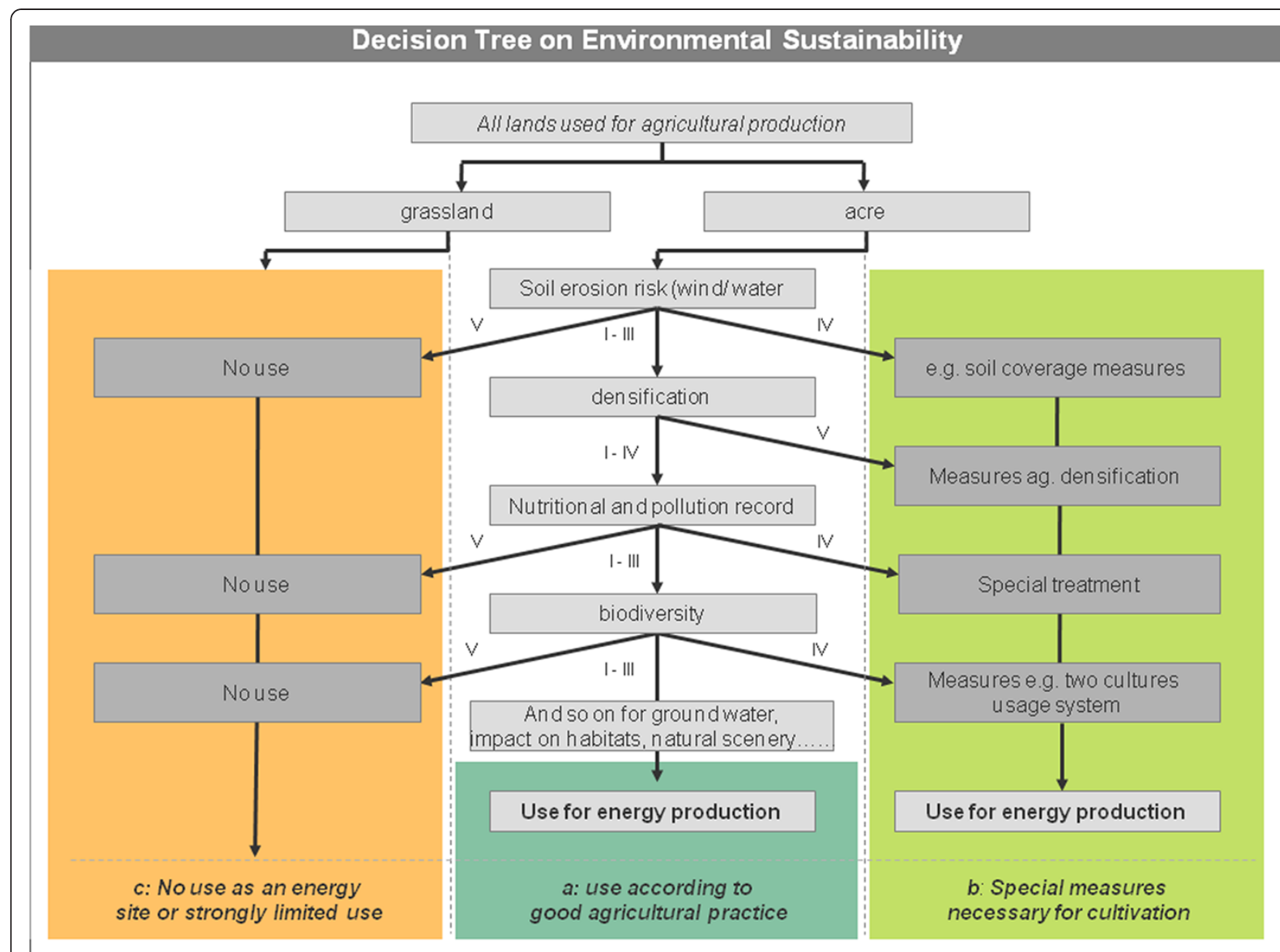

Figure 6 Decision tree for environmental sustainability according to [19][9].

system boundaries compatible to the requirement of the GHG efficiency and, thus, to guarantee a methodological blending, this modelization was not undertaken. For this purpose, a more feasible approach needs to be discovered in the future.

Damage risks to the landscape scenery have been identified: Impairment via obstructing visual axes is sitespecific, and its risk is well represented in the methodology. The quantitative development and change in the crop species composition and the deriving risk of changes regarding the appearance of a region-specific cultural landscape can even affect the expectations of tourists or the locals' sense of home, but the possibility to observe this in a crop-specific way is limited. As with biodiversity, a cumulative view has been missing so far; this makes a discursive process in every region necessary as well as monitoring the changes in terms of a reference scenario.

There is also a more pressing need for research on the impact of agricultural cultivation on water quality according to the Water Framework Directive. A transferable evaluation method is yet to be developed.

\section{Combining the requirements}

Environmental sustainability has resulted to be the most site-specific criterion; therefore, the possibility to combine it with the other two criteria is crucial. The combination of all three components in one single map has been classified as neglectable. By bringing together the requirements and assessment results of agricultural profitability and environmental sustainability, clear regionspecific conflicts were observed in the model regions, e. g., for maize silage, whose impact intensity (compared to the referral crop winter rye) is evaluated as 'negative' to 'considerably negative' regarding all environmentally protected goods, with the exception of the habitat function of mammals. As maize is one of the most profitable energy crops within the current funding system, consequential conflicts can be expected. In contrast, a synergy effect between environmental sustainability and agricultural profitability can be observed for sugar beet since its cultivation is not only rarely profitable, e.g., in the SHK but also not environmentally sustainable.

Again, overlaid with the results of environmental conservation in a mutual map (similar to Figure 7), the 


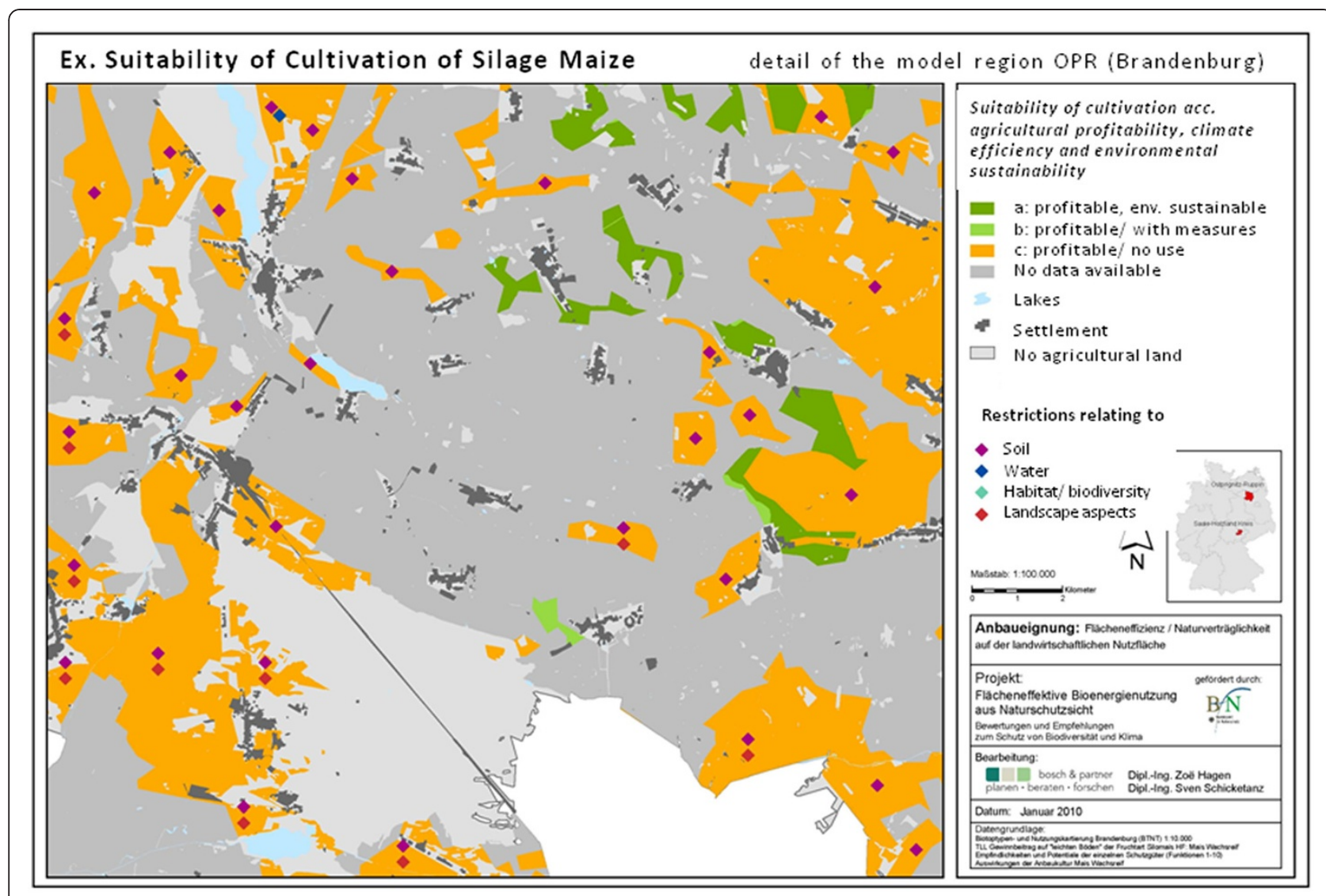

Figure 7 Profitability and environmental sustainability of cultivation of silage maize (own results) [9].

trade-offs for different energy scenarios can be clearly displayed and discussed in order to balance the regional renewable energy goals with other sustainability criteria. The methodological concept helps to explain the particular limits relating to the cultivation of agriculturally efficient crops. This confirms the expansion of determined bioenergy paths as well as the policy measures and recommendations for action.

From the perspective of the GHG efficiency, an extensive synergy with environmental sustainability can be observed: The cultivation of energy crops on permanent grassland (on organic soil) is only partially suitable in relation to both criteria. Further synergies arise for sites and crop species that are recommended according to both criteria, such as the cultivation of poplar or Miscanthus under certain conditions.

The combination of the GHG emissions and the agricultural profitability is methodically not correct because of the different system boundaries, but because the most assessed crops show the same results concerning their (economic or climate) sustainability, no further conflicts between profitability and climate change aspects are expected. This strongly not applies for energy crop cultivation on organic soils or fen sites under any condition.
The methodology is transferable to other regions. The results are basically transferable with respect to the criteria of climate efficiency, but they are region-specific regarding agricultural profitability and site-specific regarding environmental sustainability, which make the results strongly dependent on the local scenery.

\section{Discussion}

\section{Discussion of the methodological approach}

The central idea of the integrated assessment of bioenergy production is to meet sustainability goals [29] under best economic conditions. The three central sustainability requirements for bioenergy use can be integrated satisfactorily into one methodological concept. The method allows options of bioenergy pathways to be identified, which are economically reasonable by considering both aspects of climate mitigation and environmental sustainability of bioenergy systems at the same time. The possibility to locate and display site-specific environmental conflicts and potentials assures a high level of transparency for public discussion and governance.

Cumulative effects that influence habitat functions or the landscape scenery can only be described in a qualitative way. By assessing scenarios (e.g., a region decides to 


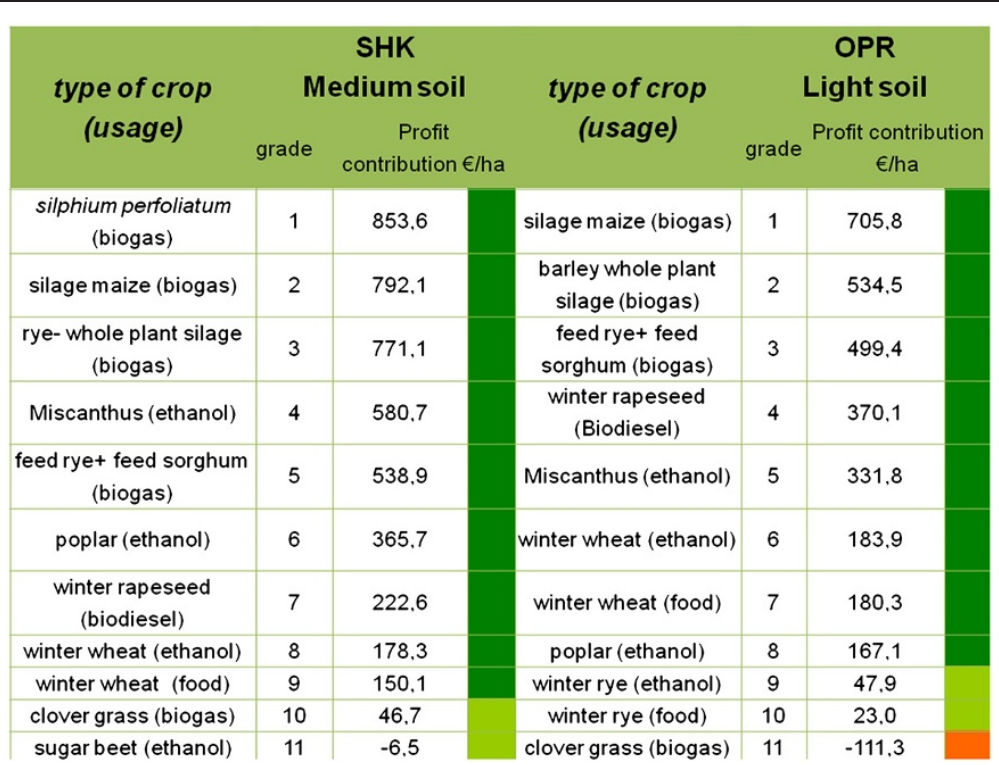

Figure 8 Agricultural profitability of selected crops (modified from Beck in [9]). The colors indicate the land category: green, profitable/land category a; light green, profitable under certain conditions/land category b; orange, not profitable/land category c.

maximize their reduction of GHG or decides to increase the bioenergy output), areas of risk and/or opportunities for agricultural profitability or environmental goals can be visualized ( $c f$. Figure 7). This procedure clarifies the competing targets and allows for the location of the origin of limiting aspects and possible mitigation measures. The integrated method also allows for the indication and spatial location of a region's maximum economic and ecological limits by considering both the actual and the planned bioenergy facilities. The latter, however, needs a further development of the methodology. The integration of the exact position of the bioenergy facilities should be easily done, such as their need of substrate, but the correlation of its provenance is complex because of data availability. So far, all assessment results have to be seen as an approximation - they could represent an important background for political discussion and decisions but are not legally binding in any way. The integration of a real-time display of current regional crop dispersal is far more difficult. Prospectively, this could lead to an improvement and regionalization of good agricultural practice and increased flexibility of assessment and planning [30]. In doing so, informal suggestions for the concretization of aims and measures regarding the planning and governance/

\begin{tabular}{lcccccc} 
& \multicolumn{2}{c}{ fallow land } & \multicolumn{2}{c}{ cereal SC. } & \multicolumn{2}{c}{ grassland SC. } \\
& dLUC & ILUC & dLUC & iLUC & dLUC & iLUC \\
rapeseed & + & + & + & + & + & - \\
wheat & + & + & + & + & + & - \\
rye & + & + & + & + & + & - \\
sugar beet & + & + & + & + & + & - \\
barley whole plant & + & + & + & + & + & - \\
silage & & & & & & + \\
rye whole plant silage & + & + & + & + & + & - \\
silage maize & + & + & + & + & + & - \\
clover grass & + & + & + & - & + & - \\
silphium perfolatum & + & + & + & + & + & - \\
feed ryel-sorghum & + & + & + & + & + & - \\
poplar & + & + & + & $(-)$ & + & - \\
miscanthus & + & + & + & $+(-)$ & + & $(-)$ \\
wheat straw & + & + & + & + & + & +
\end{tabular}

Figure 9 Results of climate balance of selected crops in reference scenarios (modified from [9]). 


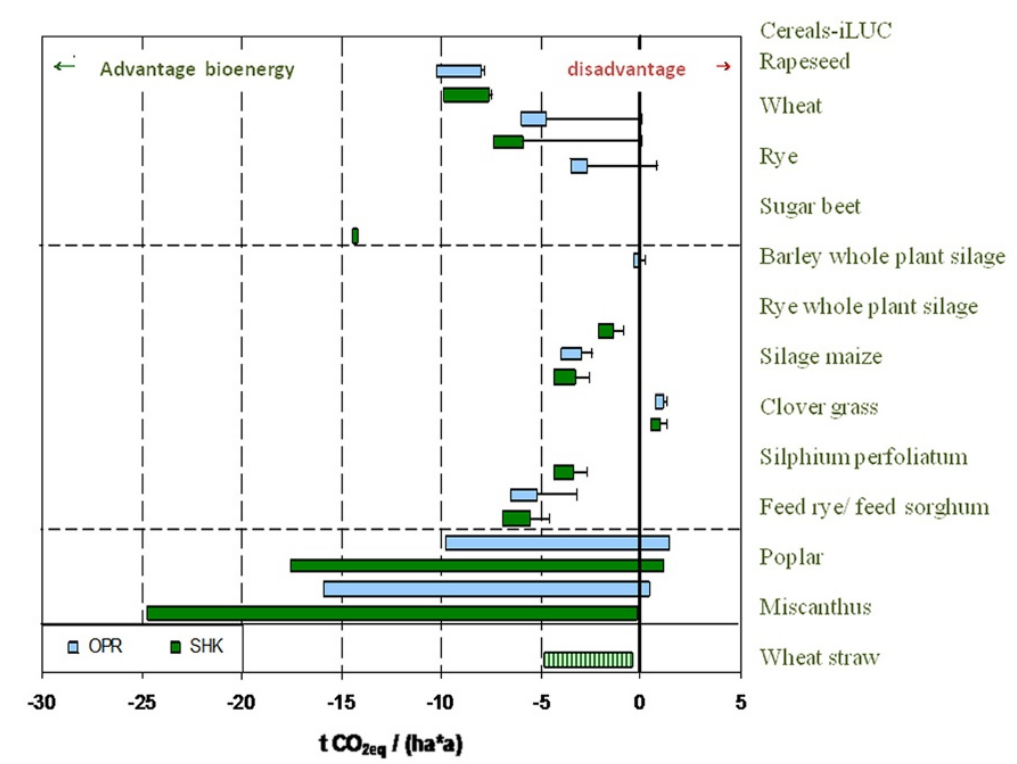

Figure $10 \mathrm{GHG}$ emission. Results in $\mathrm{CO}_{2 \text { eq }}$ for various crops within the cereals/indirect land use scenario (modified from [9]).

regulation process or for investment decisions (as for large projects) could be derived. Through agricultural consulting and adaptation of funding conditions, cultivation could be optimized by respecting area peculiarities and local sensitivities regarding environmental sustainability and GHG efficiency, which is also in the interest of most farmers [21]. In order to evaluate the crop species apart from the current funding system, such aspects have to be accounted for in the calculations.

The greatest current challenge with regard to the balance of the GHG emissions lies in displaying those considering changes in land use within the life cycle assessment in a proper way. Although there is a broad consensus on the evaluation of direct changes in land use and a discussion about the exact extent of an original carbon stock change or write-off period, an adequate methodology for quantifying the associated impact with regard to the indirect changes in land use is, according to IFEU, still lacking $(c f .[9,28,31])$. None of the existing models is representing the indirect land use changes adequately [32]. Because in this study it was not possible to develop more adequate models, further research will be necessary.

An integration of the three criteria into a combined assessment is possible, although system boundaries are not yet completely compatible. This is because the economic view (represented by the agricultural profitability) of this project follows a microeconomic approach and a site-specific system assessment within the farmland boundaries, whereas the system boundaries regarding the GHG emissions and environmental sustainability do go further. Hence, the results of two of the three criteria can be combined, but not all three. This would necessitate a comprehensive economic assessment that comprises transport and conversion.

The distinction between food and energy crops occurring in this case is sensible and necessary regarding the assessment of environmental sustainability since their slightly different cultivation methods or harvest schedules have an impact on the habitats and, therefore, on biodiversity. From an overall view, a comprehensive assessment of agricultural production is more sensible than a distinction in food/fodder and bioenergy crops. Crop rotation has not been considered here and deserves a further development of the methodology.

Basically the methodology is transferrable to other regions. However, its practical applicability is limited because of a lack of regional data availability and data preparation, which is not yet adapted to the new demands of the landscape as an energy supplier.

The use of generalized impact factors and the definition of impact intensities of energy crops are discussed controversially, especially for its use within the assessment of agricultural land use. The site-specific natural sensitivity, the impact of varying and until now not documented farm management practices, and their numerous reciprocal effects are difficult to grasp in a mutual method. The cause-effect chains of varying cultivation methods in different areas require further research, especially with regard to increasing soil degradation in many regions [33-35].

As mentioned in the introduction, the eco-political goals of the expansion of renewable energy sources lie in the reduction of greenhouse gases within electricity production 
and the avoidance or mitigation of negative impacts on the environment. With respect to biomass use for electricity production, a major goal is to maintain agricultural costeffectiveness in order to maintain the motivation of the agrarian sector to invest as well. Biomass production has to be seen as one of the alternatives within the agrarian production. It, therefore, should be assessed as such including the possibility of rising pressure on land, causing direct and indirect land use changes.

As shown, the latter as well as the conversion efficiency of bioenergy plants has the biggest impact on greenhouse gas emissions. Further development of the methodology on a regional level, including the entire agricultural production, could well describe and evaluate the impact of the intensified land use and, therefore, contribute to an improved sustainability performance. This also holds true for the assessment of environmental sustainability [36].

\section{Suitability of the methodology within the current planning system}

The recommendations drawn from scientific research can only deliver the basis for a regulatory framework and governance measures in this field. Within the current planning system, the government of energy crop production requires the collaboration of different competence authorities to consider sustainability aspects. The actual governance approach and formal reality are, therefore, not suitable to consider sustainability in a satisfying manner. The existing possibilities to apply the developed methodology, the recommendations for integration, and further demands of research or political changes in order to account for better sustainability performance within the German planning system are discussed in the succeeding paragraphs, within the existing regulatory framework.

The current possibilities to regulate and govern the energy crop production are characterized by a lot of different responsibilities and subsidy origins, levels of impact and juridical areas of coverage, each linked to a specific governmental goal. Due to its position between the state and communal levels, the appropriate scale to match these various goals concerning energy crop production is at regional level. It is possible to transform the national bioenergy production goals regarding the achieved production output and to deduce these demands for different regions, resulting in goals for every region. Regional planning authority as a link between state and communal planning could theoretically align regional goals of environmental protection and landscape preservation with goal-oriented governance of energy crop cultivation, making them compatible with each other and implementing regulatory measures. In reality, regional planning has so far been limited to informal propositions for regional governance, e.g., through the development of regional energy strategies.

In accordance with this, regional planning could make an indirect yet goal-oriented governance of energy crop cultivation possible [37]. Different time frames must be considered here: agricultural cultivation is subject to short-term decision-making and can change annually, whereas regional plans help to establish long-term zoning plans and are difficult to adjust to, e.g., scientific discoveries on production management or new breeds. Flexible solutions must be found for the integration of agricultural land use into regional planning in order to prevent the region from being harmed $[37,38]$.

In general, the instrument of landscape planning is meant to be ideal for localizing potential synergies and conflicts between environmental protection and energy crop cultivation as well as for delivering technical information for the governance of sustainable energy crop cultivation. However, it must be further developed or complemented as it does not meet the requirements at present. The methodological concept developed here can help to assess the impact and opportunities that cultivation has on flora and fauna under the current planning conditions by displaying the sensitivity of natural goods regarding crop production. It would be reasonable to compile an additional map to the landscape plan for the cultivation of energy crops. This can be important for regional planning authorities, providing a basis for agricultural consulting concerning sustainable energy pathways as well as a supplement for reports on regionally significant projects in the energy sector.

For the protected areas, the methodical concept can help to identify concrete site-specific demands that can contribute to shape agricultural management conditions. The selective designation of conservation areas and/or detailed definitions of existing land protection ordinances should lead to both proposals for environmentally sustainable areas for crop cultivation and clearly-formulated restrictions, especially in areas with highly-valued biological diversity, species protection, or protected landscape elements (A Mengel, personal communication). However, the formulation of goals within the existing regulation of protected areas is often not adequately tailored to the potential impact of energy crop production. ${ }^{\circ}$

There are also indirect opportunities for the governance of energy crop cultivation at regional and local levels with respect to the planning and approval procedure of bioenergy facilities. This is due to the fact that they are subject to the autonomy of farmers as long as they account for good agricultural practice. From a technical point of view, it makes sense to consider the potential impact of energy crop cultivation, as rendered possible with the implementation of the developed methodology, 
in building/development plans and authorization procedures (e.g., building permits, emission control permits) of a facility. Its application would improve licensing requirements and agricultural consulting about the conception and technical organization of a facility. ${ }^{\mathrm{p}}$ Some bioenergy facilities, the ones approved in accordance with the Federal Emission Control Act, undergo an environmental sustainability assessment due to their size. ${ }^{\mathrm{q}}$ This does not include biomass cultivation since it has not been requested by law.

Indirect effects resulting from changes in agricultural land use during the operation of a facility, along with cumulative effects, are also not dealt with at any stage. Neither in conjunction with the licensing procedures nor with other environmental assessments such as the flora-fauna-habitat impact assessment [25].

Since regions cannot put forward their own support programs, opportunities to influence governance of bioenergy facilities and their sustainable use by monetary support instruments are generally quite limited. Funds from the second pillar of agricultural subsidies (ELER) serve country-specific programs such as KULAP. These programs could support farmers who engage in the production of environmentally sustainable biomass cultivation [9]. Innovative cultivation systems and environmentally sustainable forms of diverse substrate production could be supported by the Agrarian Environmental Program. The corresponding benefits would incentivize farmers to pursue new crops and cultivation methods that could be grown in a more environmentally sustainable way or contribute to species diversity/preservation. There have been already many good examples of successful implementations of these programs [9].

\section{Conclusions}

An integrated assessment of biomass-based energy production paths with regard to the three criteria of agricultural profitability, climate efficiency, and environmental sustainability is possible, but strongly site-specific. A further demand for the governance of biomass cultivation would, thus, be the regionalization of the Renewable Energy Sources Act ${ }^{r}$ in order to optimize the monetary incentives of a modified bonus system for site-specific energy crops. This applies equally to all other instruments such as support, market-incentive, and investment assistance programs.

The governance of biomass cultivation is increasingly recommended by the informal governance sector within the framework of an energy concept. If one takes the entire agricultural production into account, assessment concepts such as the one introduced here can make a valuable contribution to the optimization of cultivation systems. The results showed that cup plants (S. perfoliatum) are more economically profitable than maize on the medium soil in Thueringen. Results like this could contribute to a better sustainability performance if considered within agrarian consultation. Such a methodology can detect and counteract risks that occur during the shift of the alignment of agricultural production. Until now, the consequences of these shifts have only been observed when the facilities are operating. The different requirements regarding energy crop cultivation and the partially convergent environmental goals have been examined in this article. The broad variety of stakeholders in this complex process with their individual aims in a conflictual political field clearly demonstrate that the methodology introduced here can only be a first step towards a process that balances the three goals of agricultural profitability, climate efficiency, and environmental sustainability. In addition, it has become clear that there are still a lot of knowledge gaps in this field, which should be the focus of further research. This could help to steer the process more clearly towards the achievement of these goals and give the political framework a more solid scientific basis.

\section{Endnotes}

${ }^{a}$ EEG (2000) Erneuerbare Energien Gesetz (Renewable Energy Act): Gesetz für den Vorrang Erneuerbarer Energien vom 29/03/2000. BGBl I 2000, S. 305.

${ }^{\mathrm{b}}$ Environmental goods are defined and protected by the BNatSchG (Bundesnaturschutzgesetz/Federal Nature Conservation Act). They consist of the biotic and abiotic ecosystems and their reciprocal effects. Abiotic goods are soil, water bodies, seascape, climate, air, biotopes, and landscape aspects. Biotic goods are fauna and vegetation.

${ }^{\mathrm{c}}$ There are already concepts of conducting a GISsupported assessment of environmental sustainability and cost-effectiveness for crops on an operational level. These include MANUELA (Management System of Environmental Protection for Sustainable Agriculture, Leibniz University, Hannover), REPRO (Institute for Agricultural Science, MLU Halle-Wittenberg), and KUL (Criteria for Environmentally Sustainable Land Management, LfL Agroecology). None of these are dealt with here due to the focus on the regional level.

${ }^{\mathrm{d}}$ The Fraunhofer Institute for Environmental, Safety and Energy Technology (UMSICHT) is presently conducting a joint study with the BMBF called 'The elimination of technical, legal, and economic constraints on the feed-in of biogenic gases to the natural gas network and toward the reduction of emissions through the construction and application of a geo-referenced database - strategy development for political and techno-economic implementation' (abbreviated title: Biogas Feed-In). Cf. Fraunhofer Umsicht [39] and [40]. 
${ }^{\mathrm{e}}$ From the universities of East Anglia and Exeter, Rothamstead Research, the Game and Wildlife Conservation Trust and the Centre for Ecology and Hydrology. Further information available at www.relu.ac.uk.

${ }^{f}$ Detailed discussion see [41], discussion on SAapproach compare with [42].

${ }^{\mathrm{g}}$ Further information available at [43].

${ }^{\mathrm{h}}$ The economic data apply exclusively to the observed sites and the assumptions made here (microeconomic approach, property boundary system). Transferring this to other soil conditions and/or to other soil-climate sites is, thus, not possible.

${ }^{\mathrm{i}}$ A clarification of the economic effects of different soil classes can be observed in diesel fuel consumption (in liters per hour, $\mathrm{l} / \mathrm{h}$ ), which is $4.3 \mathrm{l} / \mathrm{h}$ for $34-\mathrm{kW}$ tractors (for soft soil) and 27.2 l/h for 216-kW tractors (for hard soil, higher resistance) [9].

${ }^{j}$ Despite standardization, the results of the eco-balance assessment varied considerably to some extent. This could be due to a number of causes: (a) varying definitions of the goals and analysis frameworks in the study, including differing system boundaries (such as not considering changes in land use), (b) different basic data (such as $\mathrm{N}_{2} \mathrm{O}$ emission factors), or (c) differences in the assessment of by-products (substitution and allocation, respectively) [9].

${ }^{\mathrm{k}}$ The correlation from impact intensity to sensitivity of the water bodies though needs further research; therefore, it was impossible to assess this criterion at present.

${ }^{\mathrm{l}}$ The assessment's methodology was analogous to that of [19] and resulted in three land categories. Only a- and c-lands were pertinent for climate efficiency.

${ }^{m}$ Due to a concentration on examples such as medium soil in SHK, Thueringen and light soil in Brandenburgs' model region OPR, it is not possible to calculate or produce results for the entire region, but only for these soil qualities. In each case, only the primary soil class of each region was assessed.

${ }^{n}$ The identification of the impact intensity of energy crops requires the knowledge of different cause-effect relationships that are currently the subject of intense fundamental research. Not only research findings from the EVA Projects I and II and SUNREG II and III regarding the impact of energy crop cultivation on the landscape functions and biological diversity are available but also the key findings on the impact intensity and the characteristics of a number of crops. They are, however, too broad to support the risk assessment, above all with regard to the cumulative effects of real life evidence. Further information EVA: 'The development and composition of optimal cultivation systems for the production of energy crops according to local conditions in Germany' (EVA) I and II, joint research project of the Federal Ministry of Food, Agriculture and Consumer
Protection (BMELV) and the Agency for Renewable Resources (FNR), cf. [44] and SUNREG: Joint project of the German Environmental Foundation, the Volkswagen Foundation, and the Lower Saxony Ministry for Rural Areas, Food, Agriculture and Consumer Protection, Leibniz University Hannover, Institute for Environmental Planning (IUP)/Leibniz Institute for Agricultural Engineering Potsdam-Bornim e.V. (ATB).

${ }^{\mathrm{o}}$ In addition, respecting these rules is generally not adequately monitored, which hinders their protective effects and is often due to a lack of personnel capacity in state agencies (A Mengel, personal communication).

${ }^{\mathrm{P}}$ Germany distinguishes between two types of bioenergy facilities since the introduction of the federal building code (EAG-Bau). Biogas facilities are privileged when they have a regional-functional relationship with an agricultural factory that is affiliated with block heat and power plant (Blockheizkraftwerk) and when they have a maximum capacity of $500 \mathrm{~kW}_{\mathrm{el}}$ or where at least $50 \%$ of the biomass comes from the factory itself or one nearby. Such facilities do not require a special assessment. Non-privileged bioenergy facilities require a development plan before receiving authorization and are subject to environmental assessments. Here, a community has the opportunity to take the potential impacts of biomass preparation into consideration and to integrate criteria for environmentally sustainable, climate efficient, and profitable biomass cultivation. Afterwards, communities can work towards binding facility operators to a legal contract that only allows them to use biomass produced according to these specific requirements. The indirect effects resulting from the cultivation of biomass are not subject of the assessment, which also does not take land use change into consideration [45]. Moreover, evidence suggests that obtaining these privileges is not site-specific. An assessment of the indirect impact on land use during licensing procedures is only partially possible. Authorizing a facility (depending on the size according to building law or the Federal Emission Control Act) as a bound decision does not balance the interests of competing public issues vis-a-vis the facility and its impact on energy crop cultivation. Indeed, regional planning authorities are requested to report on large facilities. Indeed, this practically never occurs because of the absence of appropriate assessment instruments [35].

${ }^{\mathrm{q}}$ According to the law referring to environmental sustainability assessment (UVPG) in the draft announcement of 25 June 2005.

${ }^{\mathrm{r}}$ The necessity of a regionalization of good agricultural practice and supporting funding is supported by many experts $[6,14,24,25,33]$ among others. E.g. the control mechanisms applied in the Cross Compliance Rules could be tied in with the Renewable Energy Sources Act. According to Gaertner et al. [25], the Cross Compliance 
Rules have resulted in considerable effects. Until now, this regulation has been used in a very limited way in Germany. In order to do this however, requirements must be formulated in regard to the specific region. This type of specification could draw upon the criteria developed within this methodological concept.

\section{Abbreviations}

dLUC: direct land use change; EEG: German Renewable Energy Act (Erneuerbare Energien Gesetz); GHG: greenhouse gas; GIS: geographic information system; iLUC: indirect land use change; OPR: Ostprignitz-Ruppin, Region of Brandenburg (Germany); SHK: Saale-Holzlandkreis, Thueringen.

\section{Competing interests}

The author declares that she has no competing interests.

\section{Acknowledgements}

With special thanks to: Nils Rettenmaier, Dr. Guido Reinhardt \& Sven Gärtner (IFEU), Judith Beck, Dr. Katja Gödeke \& Dr. Armin Vetter (TLL), Wolfgang Peters \& Sven Schicketanz (Bosch \& Partner), with whom I worked on the project "Flächeneffiziente Biomassenutzung aus Naturschutzsicht" for the Federal Agency for Nature Conservation. Results concerning the GHGefficiency have been conducted by the IFEU, and results regarding the agricultural efficiency have been elaborated by the TLL, mainly by Judith Beck, and are basically taken from our report.

\section{Received: 24 August 2011 Accepted: 28 June 2012}

Published: 7 August 2012

\section{References}

1. Faulstich M, Greiff KB (2008) Klimaschutz durch Biomasse. Umweltwissenschaften Schadstoff-Forschung 20(3):171-179. doi:10.1007/ s12302-008-0008-2

2. German Advisory Council/SRU (2011) Pathways towards a 100\% sustainable electricity system, Special report., Berlin

3. Schütte A (2007) Projektförderung als Beitrag zur Optimierung des Energiepflanzenanbaus, In: Schriftenreihe "Nachwachsende Rohstoffe"Symposium Energiepflanzen. Fachagentur Nachwachsende Rohstoffe e.V. (FNR), vol 31. Verlag TH Mann GmbH \& Co KG, Gelsenkirchen

4. Hagen Z (2009) Aktuelle Umsetzung von Bioenergie in Brandenburg: Biogasanlagen in landwirtschaftlichen Betrieben, ZALF (Hrsg.) 2009: Aktuelle Umsetzung von Bioenergie in Brandenburg - eine Befragung Brandenburger Landwirte. ZALF-FNR-Projekt, FKZ 22020305, Gülzow, pp 6784 and $103-124$

5. BMU/BMELV (2010) Biomasseaktionsplan., http://www.bmelv.de/cln_181/ SharedDocs/Downloads/Broschueren/BiomasseaktionsplanNational.pdf? _blob=publicationFile. Accessed 12 Nov 2010

6. Bruns E, Ohlhorst D, Wenzel B, Köppel J (2011) Renewable energies in Germany's electricity market - a biography of the innovation process. Springer, Dordrecht

7. Lobley M, Winter M (2009) Knowing the land. In: What is land for? The food, fuel and climate change debate. Earthscan, London

8. Saathoff W, Von Haaren C (2010) In: Reich M, Rüter S, Energiepflanzenanbau und Naturschutz (eds) Landwirtschaft und Klimaschutz: Relevanz der landwirtschaftlichen Flächennutzung für den Klimaschutz, Umwelt und Raum, vol 1. Cuvellier, Göttingen

9. Hagen Z, Schicketanz S, Peters W, Rettenmaier N, Gärtner S, Reinhardt G, Beck K, Gödeke J, (2010) Bosch \& Partner, Thüringer Landesanstalt für Landwirtschaft (TLL) \& Institut für Energie- und Umweltforschung Heidelberg GmbH (IFEU): Flächeneffektive Bioenergienutzung aus Naturschutzsicht - Bewertungen und Empfehlungen zum Schutz von biologischer Vielfalt und Klima. F+ E Vorhaben im Auftrag des Bundesamtes für Naturschutz FKZ 3508830300

10. SRU - Sachverständigenrat für Umweltfragen (Hrsg.) (2007) Klimaschutz durch Biomasse, Sondergutachten. Schmidt, Berlin

11. Glemnitz M, Platen R, Hufnagel J (2010) In: Reich M, Rüter S (eds) Energiepflanzenanbau und Naturschutz, Umwelt und Raum, Band 1. Göttingen, Cuvellier

12. Hufnagel J, Glemnitz M, Willms M (2007) Ökologische Begleitforschung zum Energiepflanzenanbau. In: Fachagentur Nachwachsende Rohstoffe e.V. (FNR).
Symposium Energiepflanzen, Logenhaus Berlin, October 24-25 2007, vol 31. Verlag TH Mann GmbH \& Co KG, Gelsenkirchen

13. Jandewerth M (2008) Energie aus Biomasse - Aufgaben für die Raumplanung?: aktuelle Situation, Entwicklungen und Instrumente. In: GISgestützte Analyse der Biomasseproduktion im Raum - Analyse der Raumbedeutsamkeit von Flächennutzungsoptionen, Internationaler Workshop, Leipzig, 17-18 November 2008. Deutsches BiomasseForschungsZentrum gemeinnützige $\mathrm{GmbH}$ - DBFZ

14. Haughton J, Bond AJ, Lovett A, Dockerty T, Sünnenberg G, Clark SJ, Bohan $D A$, Sage RB, Mallot MD, Mallott VE, Cunningham MD, Riche AB, Shield IF, Finch JW, Turner MM, Karp A (2009) A novel, integrated approach to assessing social, economic and environmental implications of changing rural land-use: a case study of perennial biomass crops. J Appl Ecol 46:315322

15. Lovett AA, Sunnenberg GM, Richter GM, Dailey AG, Riche AB, Karp A (2009) Land use implications of increased biomass production identified by gisbased suitability and yield mapping for miscanthus in England. Bioenergy Res 2:17-28

16. Brozio S, Piorr H-P, Torkler F (2006) Tagungsband, 26. Jahrestagung der Gesellschaft für Informatik in der Land-, Forst und Ernährungswirtschaft e.V. In: Modellierung landwirtschaftlicher Bioenergie., Potsdam, 6.-8. März 2006, pp 45-48

17. Brozio S, Piorr H-P, Zeidler M, Torkler F (2009) Biogaspotenziale in Brandenburg: Methodik großräumiger GIS-Analysen unter Berücksichtigung von Nachhaltigkeitskriterien. Arch Forstwesen Landschaftsökologie Band 43 (1/2009):28-37

18. Brozio S, Piorr H-P, Zeidler M, Torkler F (2009) (2009) Methodik zur Ermittlung standortspezifischer Bioenergiepotenziale unter Berücksichtigung von Nachhaltigkeitskriterien am Beispiel des Landes Brandenburg. Berichte Gesellschaft Pflanzenbauwissenschaften Band 4:49-53

19. Schultze C, Korte B, Demmeler M, Heißenhuber A, Köppel J, Kleinschmidt B, Förster M (2008) Übertragbare Strategien zur naturverträglichen Biomassebereitstellung auf Landkreisebene - am Beispiel der Regionen Ostprignitz-Ruppin/Brandenburg und Chiemgau/Bayern - Endbericht des Forschungsvorhaben der Deutschen Bundesstiftung Umwelt., Osnabrück

20. Schultze C, Köppel J (2007) Gebietskulissen für den Energiepflanzenanbau. Naturschutz und Landschaftsplanung vol 9/07, 39., Jahrgang, pp pp 269-pp 272

21. ZALF/FNR (2009) Zustandsbericht zur aktuellen Umsetzung von Bioenergie auf landwirtschaftlichen Betrieben - eine Befragung Brandenburger Landwirte., Müncheberg

22. Morrison-Saunders A, Fischer TB (2006) What is wrong with EIA and SEA anyway? A sceptic's perspective on sustainability assessment. J Environ Assess Pol Manage 8(1):19-39

23. Thraen D, Seidenberger T, Zeddies J, Offermann R (2010) Global biomass potentials - resources, drivers and scenario results, 3 vol 14th edn, Energy for Sustainable Development. Elsevier

24. Von Haaren C (2004) Landschaftsplanung. Verlag Eugen Ulmer, Stuttgart

25. Gaertner S, Münch J, Reinhardt G, Koeppen S, Daniel J, Postel J, Scholwin F, Klinski S, Brohmann B, Fritsche UR, Hennenberg K, Huenecke K, Rausch L, Koeppel J, Peters W, Pusch E, Schultze C (2008) Optimierungen für einen nachhaltigen Ausbau der Biogaserzeugung und - nutzung in Deutschland. Verbundprojekt gefördert vom Bundesministerium für Umwelt, Naturschutz und Reaktorsicherheit (BMU), Forschungszentrum Jülich, Endbericht, Jülich

26. Marks R, Müller MJ, Leser H, Klink H-J (1992) Anleitung zur Bewertung des Leistungsvermögens des Landschaftshaushaltes, Forschung zur deutschen Landeskunde, vol 229. Trier, Selbstverlag

27. Müller U (2004) Niedersächsisches Landesamt für Bodenforschung. In: Auswertungsmethoden im Bodenschutz. Dokumentation zur Methodenbank des Niedersächsischen Bodeninformationssystems (NIBIS ${ }^{\circledR}$, 2004) Arbeitshefte Boden, Heft 2004/2. Hanover

28. Jungk N, Reinhardt GA (2000) Landwirtschaftliche Referenzsysteme in ökologischen Bilanzierungen, Eine Basisanalyse. Gefördert durch das Bundesministerium für Landwirtschaft, Ernährung und Forsten (BML), FKZ 99NR009. IFEU, Heidelberg

29. Schubert R, Schellnhuber HJ, Buchmann N, Grießhammer R, Kulessa M, Messner D, Rahmstorf S, Schmid J (2009) Bioenergy and sustainable land use. Earthscan, London

30. Federal Ministry of Transport, Building and Urban Development (BMVBS) (2010) How do regions prepare for climate change? Federal Ministry of Transport, Building and Urban Development, Darmstadt 
31. Reinhardt $\mathrm{GA}$ (1993) Energie- und $\mathrm{CO}_{2}$-Bilanzierung nachwachsender Rohstoffe: Theoretische Grundlagen und Fallstudie Raps. Vieweg-Verlag, Wiesbaden

32. Fehrenbach H, Giegrich J, Reinhardt GA, Rettenmaier N (2009) Synopse aktueller Modelle und Methoden zu indirekten Landnutzungsänderungen ILUC. Im Auftrag des Bundesverbands der deutschen Bioethanolwirtschaft e. V. $\left(\mathrm{BDB}^{\mathrm{e}}\right)$. IFEU, Heidelberg

33. Glemnitz M, Hufnagel J, Willms M (2009) In: Zentrum für Agrarlandschaftsforschung e.V (ed) Ökologische Folgewirkungen des Energiepflanzenanbaus - Schlussbericht zum Teilprojekt II des FNRProjektes: Entwicklung und Vergleich von optimierten Anbausystemen für die landwirtschaftliche Produktion von Energiepflanzen unter den verschiedenen Standortbedingungen Deutschlands (EVA)., Müncheberg

34. Nehring A, Vetter A (2009) Entwicklung und Vergleich von optimierten Anbausystemen für die landwirtschaftliche Produktion von Energiepflanzen unter den verschiedenen Standortbedingungen Deutschlands (EVA). In: Thüringer Landesanstalt für Landwirtschaft (ed) Entwicklung und Optimierung von standortangepassten Anbausystemen für Energiepflanzen im Fruchtfolgeregime - Schlussbericht zum Teilprojekt I des FNR-Projektes., Jena

35. Regionale Planungsstelle P-O (2010) F+E-Vorhaben im Auftrag des Bundesamtes für Naturschutz, FKZ 3508830300 with employees of the Regionale Planungsstelle Prignitz-Oberhavel and the county of OPR. In: Personal communication, presentation and discussion of the project Flächeneffektive Bioenergienutzung aus Naturschutzsicht - Bewertungen und Empfehlungen zum Schutz von biologischer Vielfalt und Klima., 25 Jan 2010

36. Jessel B (2009) DBFZ: Biomass in future landscapes. In: Nachhaltige Nutzung von Biomasse - Synergien und Risiken im Hinblick auf den Landschaftsund Naturschutz. Proceedings of the Conference, Berlin, 31 March - 1 April 2009

37. BMVBS (2010) Globale und regionale Verteilung von Biomassepotenzialen. Status-quo und Möglichkeiten der Präzisierung, Bundesinstitut für Bau-, Stadt- und Raumforschung (BBSR) im Bundesamt für Bauwesen und Raumordnung (BBR), Bonn

38. Mengel A (2009) Internationale Naturschutzakademie Vilm, Vilm 18-20 November 2009. In: Steuerung des Ausbaus der Erneuerbaren Energien Instrumente und Handlungsoptionen

39. Fraunhofer UMSICHT (2012) Abschlussbericht., http://www. biogaseinspeisung.de/ergebnisse/bericht/. Accessed 6 May 2012

40. Schuck O, Seidel O, Scholwin F, Weithäuser M, Dresen B, Jandewerth M, Urban W, Zeidler-Fandrich B (2009) Beseitigung technischer, rechtlicher und ökonomischer Hemmnisse bei der Einspeisung biogener Gase in das Erdgasnetz zur Reduzierung klimarelevanter Emissionen durch Aufbau und Anwendung einer georeferenzierten Datenbank, Band 6, Entwicklung und Anwendung einer GIS- Applikation zur Standortfindung und Potenzialanalyse der Biomethanerzeugung. Räumliche, ökonomisch-ökologische Bilanzierung als Bewertungsgrundlage für Energiesystemszenarien. In: Abschlussbericht für das BMBF- Verbundprojekt „Biogaseinspeisung“. Trier, Oberhausen, Leipzig, Wuppertal, Bochum, Essen, Magdeburg

41. Karp A, Haughton A, Bohan D, Lovett A, Bond A, Dockerty T, Sünnenberg G, Finch JW, Sage R, Appleton K, Riche A, Mallott M, Mallot V, Cunningham M, Clark S, Turner M (2009) Perennial energy crops: implication and potential. In: Winter M, Lobley M (eds) What is land for? The food, fuel and climate debate. Earthscan, London

42. Bond A, Dockerty T, Lovett A, Riche A, Haughton A, Bohan D, Sage R, Shield I, Finch JW, Turner M, Karp A (2011) Learning how to deal with values, frames and governance in sustainability appraisal. Regional Studies 45 (8):1157-1170

43. Fraunhofer UMSICHT (2012) Bioenergie aus der Landwirtschaft. Biogas, Bioethanol, Biodiesel, Potenzialstudien Biomasse, http://www.fh-eberswalde. de/Projekte/Bioenergie/Aktuelle-Projekte/Potenzialstudie-Biomasse/ Bioenergie-aus-der-Landwirtschaft-K755.htm. Accessed 06 May 2012

44. Eberswalde HNE (2012) Standortangepasste Anbausysteme für Energiepflanzen., http://www.eva-verbund.de/home.html. Accessed 3 Mar 2012

45. Schultze C, Köppel J, Hagen Z, Demmeler M, Korte B (2008) Wissenschaftsverbund Umwelt: Nutzungskonflikte bei nachwachsenden Rohstoffen. In: Planerische Ansätze für naturverträglichen Biomasseanbau. Rostock Universität, Rostock

doi:10.1186/2192-0567-2-16

Cite this article as: Hagen: A basic design for a multicriteria approach to efficient bioenergy production at regional level. Energy, Sustainability and Society 2012 2:16

\section{Submit your manuscript to a SpringerOpen ${ }^{\circ}$ journal and benefit from:}

- Convenient online submission

- Rigorous peer review

- Immediate publication on acceptance

- Open access: articles freely available online

- High visibility within the field

- Retaining the copyright to your article

Submit your next manuscript at $>$ springeropen.com 